\title{
Extinction and Revival
}

\author{
Yiwen Tu \\ Communications Design Department, Pratt Institute, New York, USA \\ Email: yvonnetufsh@gmail.com
}

How to cite this paper: Tu, Y. W. (2021). Extinction and Revival. Voice of the Publisher, 7, 123-145.

https://doi.org/10.4236/vp.2021.74011

Received: September 12, 2021

Accepted: December 10, 2021

Published: December 13, 2021

Copyright (c) 2021 by author(s) and Scientific Research Publishing Inc. This work is licensed under the Creative Commons Attribution International License (CC BY 4.0).

http://creativecommons.org/licenses/by/4.0/

\begin{abstract}
It is through human instinct that people preserve the endangered and resurrect the extinct. Protecting endangered animals, retrieving indigenous languages, rebuilding archaeological relics are just three examples. This also applies to larger historical events. After reaching the extreme of one ideology, any society is bound to swing back to the opposite side as it seeks a new future. While searching for this opposite idea, people usually look back into history for references, thereby reforming through revival. The revived is transformed into a weapon against current unpromising situations rather than simply as a process of reproduction of the original. Through case studies and experiential analysis, this thesis aims to study the language of extinction and revival in art and design field, and how annihilation and resurrection can be applied in design as a methodology, and how it can shape future human understanding and behavior.
\end{abstract}

\section{Keywords}

Extinction, Revival, Destroy, Resurrect, Civilization, Culture Heritage, Relic, Culture transmission, Trace, Art and Design Methodology, Design Language

\section{Introduction}

Reviving the extinct is the act of bringing back the disappeared or obsolete, and utilizing it for understanding the past, adapting it to the contemporary context, and preserving it for future exploration. The case studies presented here show three stages of annihilation and resurrection. The first focuses on a fragment of the past, reinterprets it with imagination, then turns it into a weapon against the present that people are not satisfied with. Then, after developing an extreme ideology, societies will revert to the original, revalue what had been omitted, balance and readapt it to the present. Finally, destruction for revival is an act of using the extinction to convey a message. Here, the extinct relies on reexamination, reinterpretation, and re-adaptation of the message to open up more op- 
portunities after its disappearance. Rather than an act of human nature, destroying and reviving is more of an approach for progress. Design as a means to promote progress can also use extinction and revival. This thesis intends to develop new design methodologies based on extinction and revival, to inform future human behavior and perceptions.

\section{Proposal}

From the restoration of cultural relics to the reconstruction of a lost civilization, from rescuing endangered species to retrieving indigenous languages, the cycle of destruction and restoration of the impaired has been repeated throughout human history. Although destruction and extinction are inevitable in most of the cases, societies often attempt to bring back what has been lost and keep them alive. Although there exist numerous factors that contribute to extinction, this thesis focuses on exploring the motivation and meanings of reviving the disappeared and recreating the extinct. Revival is brought about to maintain generational continuity.

So what is the motivation and role of revival in a cultural and social context? When people make a replica of something, no matter how good it resembles the original, it is always a different creature with some new interpretation ascribed to it. So what is the implication of attempting to make a replica of the past? This thesis will research this question through case studies in language, biology, architecture, ideology, and movements in history. This research explores how the process of destruction to provide responses to the following questions.

\section{Thesis Questions}

How can designers shape perception and knowledge by using annihilation and resurrection as methodologies?

What message do Reinvigoration and Destruction (as a design methodology and a design outcome) convey?

How can we use extinction and revival to inform future human understanding and behaviors?

\section{Literature Review}

When thinking of extinction and revival in modern history, the word "retro" and "nostalgia" first come to people's mind. In Elizabeth Guffy's book Retro: The Culture of Revival, she refers to "retro" as "a re-emergence of styles and fashions that evoke familiar touchstones of memory from the not-so-distant past" (Guffey, 2006). These styles that inform people in their daily lives can be easily observed in fashion, design, and music. Although retro styles are titled with trends that prevailed in the past, they usually have a disconnection between the old styles and the original contexts. According to Penny Spark, the revival of certain styles reveals the condition where this revival is taking place rather than the time those styles were created (Sparke, 2010). In other words, what triggers 
the retro style at the moment is the key to understand retro and the "not-so-distant" past. In the book review of Guffy's Retro: The Culture of Revival, Spark mentioned that as "the popular cultural machine continually demands so much new 'material'," people are inclined to look into the near past where the references are still highly accessible to them, to instantly respond to the accelerating social demand (Sparke, 2010).

However, a revival that excludes the ideology or social triggers of the past only scratches the surface. John-Patrick Hartnett's article concerning Swissted's revival of Swiss design criticized that "far from celebrating its subject matter," Swissted's project of designing music posters mimicking old Swiss design posters, then selling them "guts the meaning from history in order to sell its hollow shell as a commodity" (Hartnett, 2016). In Hartnett's opinion, applying only the form of a past style to current content without building connections or revealing deeper meaning is a depreciation where a style is just a container, and the subject is just the infill (Hartnett, 2016). By placing current issues along past contexts, revival should provoke thoughts of the revived as well as the current, and explore deeper problems that society is facing.

One successful case of reviving the extinct to communicate messages about current issues is the Renaissance movement. From the fourteenth century to the seventeenth century, the Renaissance sprang up as a consequence of prosperous commerce and the collapse of feudalism (Lee). Centuries ago, it was the Catholicism and the manorial system that caused Greco-Roman classical antiquity to go extinct. Then, the Renaissance revived the ideology of classical antiquity to fight against the obstacles to economic and social development, whether religious power or the manorial system. By reviving "science" and "humanity" from classical antiquity, a connection was built between contemporary issues and an extinct ideology; the renaissance response addressed wider social challenges.

There exists another circumstance where a subject can only be accepted through future revival. Stravinsky's Rite of Spring is one example. Due to the fact that works like Rite of Spring were too avant-garde for the society to accept at the time they were created, they became extinct on the mainstream stage (Dance Magazine, 2013). But as society evolves, it finally reaches the moment when works like Rite of Spring is embraced and appreciated. Condemned after the first performance, “Stravinsky's earth-cracking Rite of Spring has become the mountain that many choreographers feel challenged to climb-more than 30 by our count” (Dance Magazine, 2013). As long as the avant-garde (past extinct) is recognized and revived, it becomes a symbol of wisdom from the past, referenced to communicate to the contemporary. Reviving the unacknowledged can be seen as both foresight ahead of historical development and the application of the idea to contemporary social issues.

During a performance, such as Rite of Spring, if documentations are not allowed, the fact that this experience goes extinct also affects the impact of future revival. In Selfie at a Museum: Defining a Paradigm for an Analysis of Taking (Self-Portrait) Photographs at Museum Exhibitions, Chlebus-Grudzień consid- 
ers documentations such as selfies a positive phenomenon that facilitates audience's reception of the museum, broadens cultural distribution, and provides facilities feedbacks from visitors (Chlebus-Grudzień, Conclusion). However, in Social and Technological Motivations for Online Photo Sharing, Anne Oeldorf-Hirsch and S. S. Sundar listed three primary motivations of taking a photo: constructing personal or group memories, creating and maintaining one's social relationships, and self-expression (Oeldorf-Hirsch and Sundar). Also, when people focus more on the medium where they can share images, we tend to neglect the process of archiving photos and preserving memories (Oeldorf-Hirsch and Sundar). Therefore, in the digital era, taking images during an event is more about the participants themselves rather than the experience. This idea can be supported by my experience of visiting "David Bowie Is" exhibition at Brooklyn Museum in May 2018. Knowing that no personal documentation can be taken away from the experience, the visitors are more immersed in the exhibition (Orlov, 2018). Based on my research of people's reaction to this exhibition, it is shown that a no-photo-taking exhibition is more likely to trigger further actions, whether listening to David Bowie's music or searching for more information about him. And these actions along with the thoughts generated during the process are one representation of revival. To sum up, reviving the extinct does not necessarily require detailed documentation, but a deep impression or strong idea that stimulates a new idea that is inspired by the absent is essential.

Other than being a pre-condition to future revival, extinction also determines the nature and dimension of revival. On the one hand, extinction and revival are two ends in a dialogue that work together as a mechanism to create new social phenomena. On the other hand, extinction and revival reflect the law of socio-historical development. Consider a quote from one of the four classic novels of Chinese literature, Romance of the Three Kingdoms: "A perennial split is always followed by a reunion, and vice versa” (translated from “分久必合，合久必 分”) (Luo). It is a line describing the history of the late Han Dynasty as well as the entire history of the world. Here, history moves forward while going back and forth from turbulence to stability, extinction and revival. After each round, as people explore, learn, reflect and generate, history arrives at a position where the new and different emerge, serving as evidence of change, development and progress.

In a smaller scale, exterminating something that has a negative influence, or revitalizing the dead that features certain positive value reveals a human desire for control. Control, as one of the primary methods for people to "achieve pleasure, satisfaction and happiness, and to avoid suffering, pain and sorrow", motivates most human behavior (Aminoff, 2013, 2014). Aminoff defines this kind of action which brings about positive feeling as anti-entropy, in contrast to entropy, which is seen as "a degree of chaos" (Aminoff, 2014). Therefore, activities related to extinction and revival are triggered by the human desire to achieve happiness and avoid suffering. But sometimes, people also achieve happiness by transferring energy to a tangible value which lies in an object. Book restoration is 
a good example. Nature sets the book's destiny to decay over time, but through restoration process, people counter entropy by adding energy to the book. The process can be seen as a way of energy being transformed into values contained by a tangible object. Then, by possessing the object, people achieve satisfaction (anti-entropy). In another word, people are inclined to generate anti-entropic products through entropic processing.

Heiner Bubb explains the concept of entropy in relation to consumers' behavior from another angle. According to Bubb, humans (consumers) create order by using tools (products) to do routine work in order to pursue comfort (anti-entropy). The cost of the comfort is the energy consumed by the tool. However, focusing on creative work would be another exhausting process that can be defined as entropy (Bubb, 2006). The key to achieve consumer satisfaction is to keep the balance between entropy and anti-entropy. This theory can be reflected by the invention of the Risograph machine. To achieve comfort, people use technology to do the repetitive routine work involved in silk-screening. Then, worn by the continuous creative work and the lack of engagement with the printing process, people seek the balance in Risograph, which combines the virtue of technology and old technique of silk-screen.

The research described above leads to a conclusion that extinction and revival are not only driven by the basic human desire of achieving happiness, but also as a direct way of fulfilling that desire. On a larger scale, extinction and revival as a methodology may solve social problems through the development of new approaches, based on past experiences which trace the pattern of historical development.

\section{Historical Contextual}

\subsection{What Are Extinction and Revival}

Human history is filled with rises and declines, progress and reversals. The only way to learn about the disappeared is through searching in the traces of existence, discovering and reviving it. The Mayan Civilization mysteriously vanished, leaving only damaged architecture and fragmentary records. After thousands of years in Chichen Itza, the locals are revitalizing the ancient culture by replicating the Mayan calendar, reliving Mayan time, or re-enacting Mayan ritual. These behaviors of revitalizing a lost civilization serve as an attempt to attract visitors, satisfy the curiosity of unknown cultures, and fulfill the pride in the ancestors who had created countless scientifically and culturally significant wonders.

In 2016, artist Edoardo Tresoldi designed a site-specific installation at Archaeological Park of Siponto in Italy. The installation shown in Figure 1 is a see-through structure of an ancient Early Christian basilica placed next to an existing Romanesque church. The installation opens up a conversation between the past and the present and allows the audience to connect with history and time (Tresoldi, 2016). In this case, Edoardo's installation resurrected a lost relationship between the current space where people can relate to a space from the 


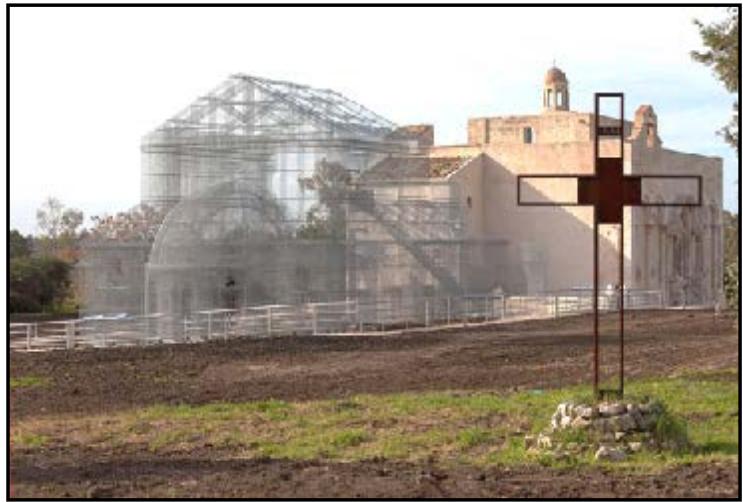

Figure 1. Etherea, by Edoardo Tresoldi https://www.edoardotresoldi.com/works/etherea/.

past. Learning what used to exist and thinking of how space evolved into the current status help people better understand the time they live in. Compared to space that has been existing for thousands of years, human lives are ephemeral. By connecting minuscule individuals to the enormous nature, we expand the meaning of our lives.

Physical artifacts aren't the only things that can be revived. Cultural symbols like indigenous languages can be brought back as well. It is predicted that at the end of this century, 7000 languages will have vanished, and linguists are making the best effort to archive endangered languages and to retrieve the lost ones. There is a similarity between saving indigenous languages and protecting extinguished species (ELA, 2012). Once a language or an animal species vanish, mankind will lose a key with which to access the diverse cultural or natural resources. There are irreversible losses that human civilization must try to avoid. The three cases mentioned above provide a general understanding of the behavior of reviving. It is an act of bringing the disappeared or obsolete back, understanding the past, adapting it to the contemporary context, and preserving it for future exploration.

\subsection{Revive for Rivalry-The Renaissance}

The Renaissance took place in Europe from the14th to the 17th century. It is a cultural movement that fought against the medieval feudalism through art, literature, philosophy, politics, science, and religion. The early 1300s witnessed the decline of the feudal system and the growth of mercantilism commerce. This provoked the belief in humanism, naturalism, and science that could be traced back to the Classic Antiquity of Ancient Greece and Roman (Lee).

Figure 2 Madonna and Child of the 13th century and Figure 3 Virgin and Child of the 15th century depict the change in people's interpretation and value of religious beliefs. In Berlinghiero's Madonna and Child, the Madonna frowns while the child Jesus appears emotionless, with no indication of any childlike innocence. It emphasizes the difference between god and mortal, by excluding human desire and feeling from god's image (The MET, 2018a). 


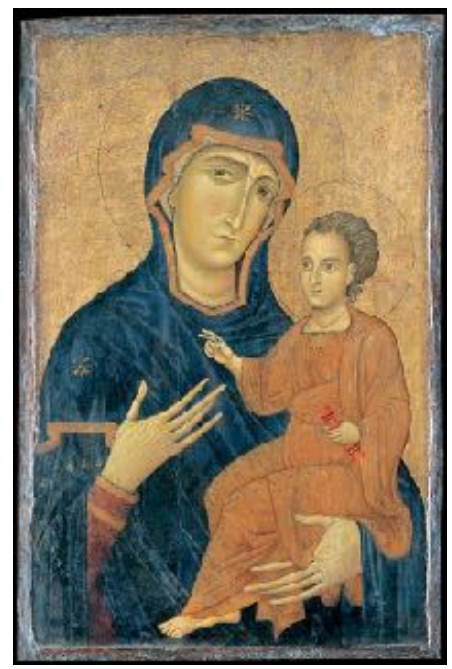

Figure 2. Madonna and Child, by Berlinghiero https://www.metmuseum.org/art/collection/search/435658.

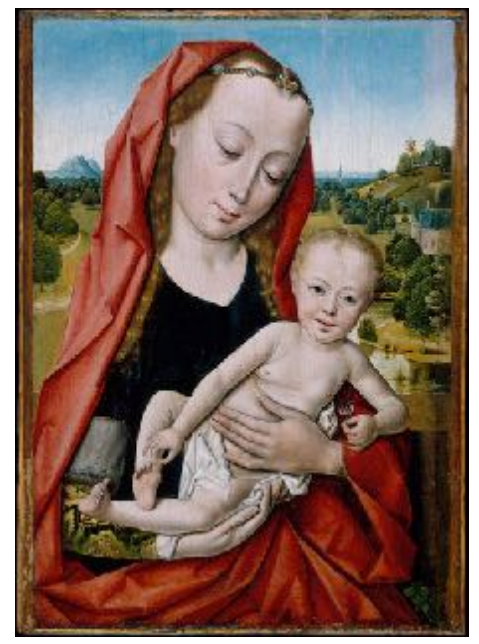

Figure 3. Virgin and Child, by Dieric Bouts https://www.metmuseum.org/art/collection/search/435765.

Then, under the influence of the Renaissance, Dieric Bouts' Virgin and Child reveals Madonna's affection and Jesus's innocence through their gestures and expressions. The movement advocated the humanity rather than degrade it as evidence of imperfection (The MET, 2018b).

However, Classic Antiquity revived in the Renaissance was not the same as the original. For instance, the Renaissance excluded the fact that Classical Antiquity was used by Emperor Augustus "to control public perceptions of the relationship between national mythology and his own political accomplishments" (Moorton \& Titchener, 1999). In contrast, the Renaissance picked out and exaggerated the parts of Classical Antiquity that best illustrated humanism, morality, naturalism, and science. In other words, it focused on a fragment of Classical Antiquity, reinterpreted it with imagination, then turned it into a weapon against the darkness of feudalism. 


\subsection{Created for Extinction-Art Reclaimed by Nature and Self-Destruction Artwork}

Jeffrey Kastner in Land and Environmental Art (pp.16-17) described the American art world in the 1960s as "a period of longing-for a future that broke with a complacent present and for a past that transcended both." The American post-war period witnessed radical changes in the consciousness of feminism, the awareness of the ecological system, lifestyles under the impact of technology, and social insecurity caused by political struggles. This context led to a pursuit of simplicity and escapism rooted in the past, and in nature. This period bred the Environmental Art (also referred to Land Art) movement which focused on exploring the relationship between humans and nature. Artist Michael Heizer's series of work Nevada Depressions serves as a great example: Figure 4 is the rift he excavated in the desert floor would disappear over time, ending a conversation with a return to nature. Michael Heizer's idea behind this work is that "time is set in relation to human scale, which seems minuscule in proportion to the immensity of nature" (Land and Environmental Art, pp.52-53).

The revival of these extinct artworks is usually conducted through the presentation of documentation as well as through the critiques people made afterward. The once existing artwork then becomes a source for reexamination, reinterpretation and re-adaptation. The process of putting the artwork back to the context when it was created serves as a reference and the beginning of new ideas that are related to time or space. These artifacts that are created to be extinct reveal its assigned meaning and opens up new opportunities when its trace gets erased.

There exists another kind of self-destructing artwork that use its own extinction to rebel against the art system. On October 8th, 2018, the auction of Banksy's Girl with Balloon ended with a dramatic self-destruction (Figure 5). After the auctioneer's hammer came down, the painting automatically passed through a built-in shredder and hung out of the frame in stripes. The gesture was meant to challenge the current condition of the art system where creativity is disrespectfully reduced to commodity (the original was a street art, framed and auctioned as a luxury painting). "You distort it; I ruin it." Here, the artist performed

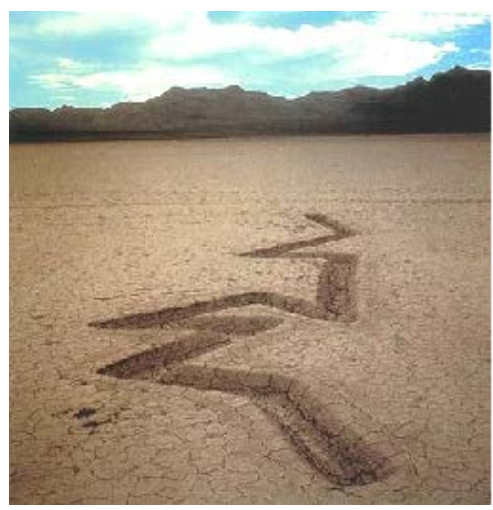

Figure 4. Rift\#1, by Michael Heizer https://theartstack.com/artist/michael-heizer/rift-1-2. 


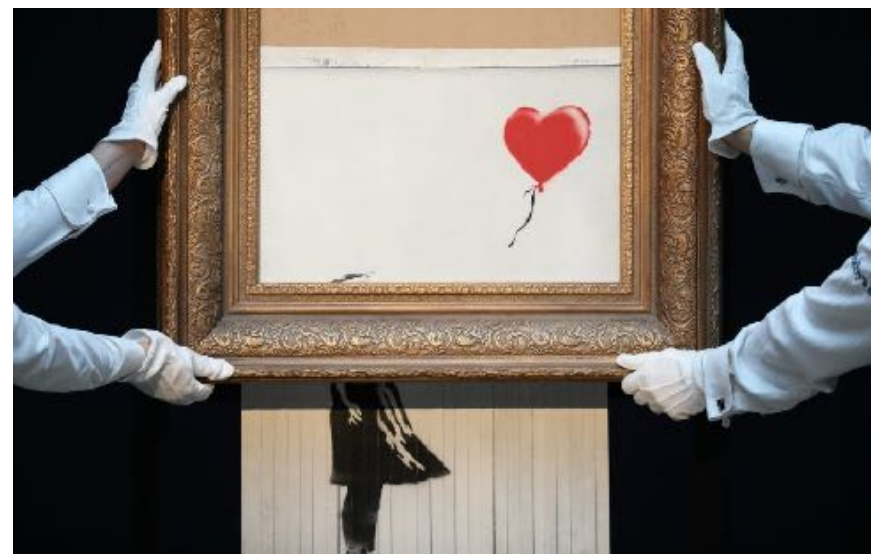

Figure 5. Girl with Balloon, by Banksy

https://www.pinterest.com/pin/90494273748692990/?lp=true.

the process of "extinction" to revive or re-emphasize on his will of creating the artwork (Jones, 2018).

\subsection{Extinction and Revival in Design}

In the article Castles Made of Sand, Lorraine Wild points out that the minimal modernism was being overvalued as "the ultimate, perfected form of visual communication." (pp.152) In a society where the audience is the consumer, design becomes a product to promote sales. This creates a system of principles that builds efficient and "perfect" design.

However, this unified aesthetic has been declining as society begins to advocate diversity and novelty. Designers explore the ways to overthrow this design ideology by challenging the technique, methodology, and visual language, thereby revitalizing the design industry. The rise of Risograph printing is one example. First launched in 1984 by Riso Kagaku Corporation of Japan, the Risograph printer produces artwork with a handcrafted touch in a mechanical way. Its current popularity is a contrast as well as the response to digital technology. Instead of creating accurate, scientific and efficient digital prints, Risograph imitates the technique of silk-screen printing which focuses more on the process of making an image. The authenticity, along with the emphasis on the process, gives the art another layer of visual impact and meaning (Webster, 2018).

In the movement against modernism, artists and designers see the risk of hanging on to one design principle that hinders the development of a new era. In the case of Risograph printing, people revived silk-screen printing and transformed it into a more efficient design tool with the help of new technology. It is the integration of the obsolete and the current. The revival fills in the blank, which is valuing the process and handcraft in the digital era, improves the technique with advanced technology, then ultimately, achieves a breakthrough.

\subsection{Extinction and Revival in Architectural Restoration}

Ever since ISIS was established in 1999, they have been destroying countless 
cultural artifacts as they believe they are examples of idolatrous (McKernan, 2016). On September 2nd in 2018, Brazil's National Museum burnt down with the loss of $90 \%$ of the museum's collection and the 200 -year-old building that was once a slave trader's home and a royal palace (Young, Ed). Throughout history, there are innumerable tragedies where the grandeur of architecture was destroyed by either uncontrollable natural disasters or anthropogenic factors. People have attempted to restore the broken and preserve the historical or social significance of the architecture because it is the symbol of a new start, as well as an attempt to build a connection with the razed or damaged.

After each destruction, there would be a debate on whether the ruined should be reconstructed or not. In The True Meaning of the Word Restoration: Architecture and Obsolescence in Jude the Obscure, Benjamin Cannon (pp.202) argued that restoration "threatens the historical continuity by approaching history as a traumatic process that must be reversed." Contrary to his idea that a piece of relic should be valued as how they presently are, this thesis believes the process of restoration is the reflection of the demand for reviving the extinct or endangered culture and ideology. In other words, revival is brought about by historical context such as social problems and social demands, thus maintaining continuity.

Also, reconstruction differs from reproduction because certain changes will necessarily be made. It is conducted based on the need of the time, society, environment, and on the relationship between these three elements. For instance, in the article Rural Habitation in Syria: The Culture of Traditional Architecture and Its Role in the Reconstruction Process, M. Wesam Al Asali and Iyas Shahin mention that architecture designers will "ensure the continuity of urban development" through "utilizing natural and local materials," while, "focusing on the organic side" (p.116). Revival through architectural reconstruction not only reflects historical significance, but also the meaning of the architecture within the modern context, and the functionality of serving the current audience.

\subsection{Extinction and Revival in Hegelian Dialectic}

The five case studies discussed above reveal a shared pattern in the process of Extinction and Revival. To begin with, the trigger of revival is always people's desires for changes to the current situation. Then, they try to find a solution or an idea by looking for opposites in the past, obsolete world. Once something is determined to be brought back, people choose the most radical ideas for exaggeration and reinforcement, thereby reviving it in the most influential way to fight against current conditions. Nevertheless, what happens after the revival is mostly the integration or mutual compromise of the two opposites, rather than return to the original status.

This pattern of historical development can be related to the Hegelian dialectic which is seen as a methodology of thinking or a theory depicting the nature of reality. Georg Wilhelm Friedrich Hegel put forward that people's perceptions are 
synthetically formed through the process of debate between thesis and antithesis (Limnatis, 2010). This philosophy can also be applied to the historical development that shares the same belief in certain periods. When this development reaches its extreme, it will swing back to the opposite side of that ideology. Every swing involves the extinction of one idea and the revival of another, and the angle of the swing becomes smaller after each loop. Then, in the end, the swing of history will stop in the middle, which is the ideal world without arguments. Figure 6 is the model depicting Hegelian dialectic.

In the Hegelian dialectic, there exists an outcome of synthesis that could be adapted to the process of Extinction and Revival. So what is the synthesis when using Extinction and Revival as design methodologies? Can design reach the final synthesis, or just keep approaching it like the model in Figure 7 ?

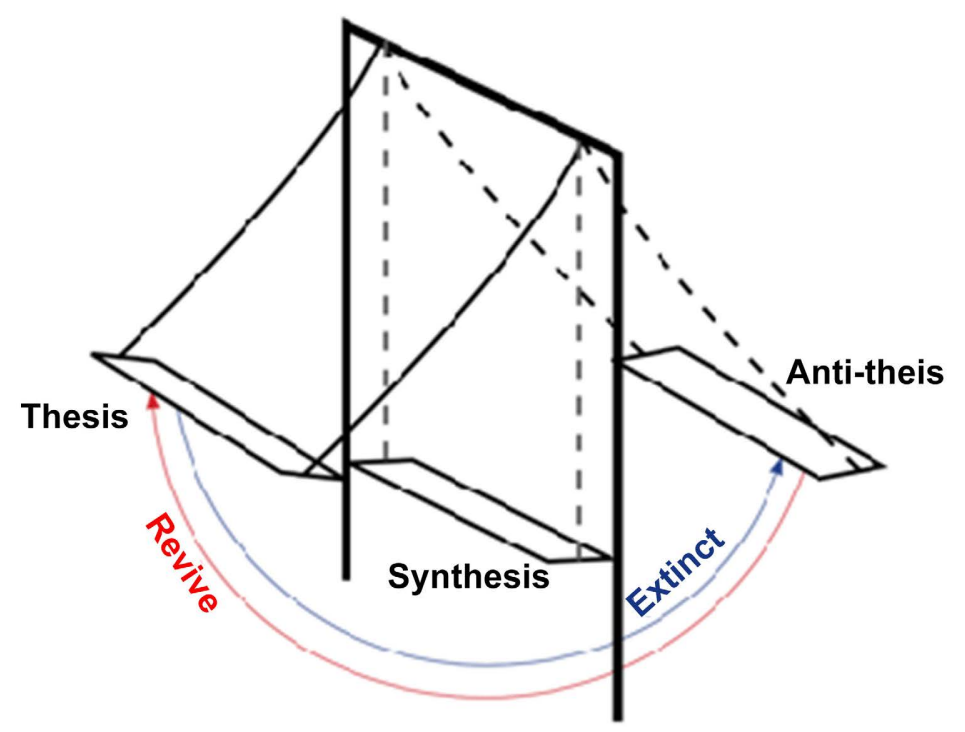

Figure 6. Model \#1 of the development of extinction and revival.

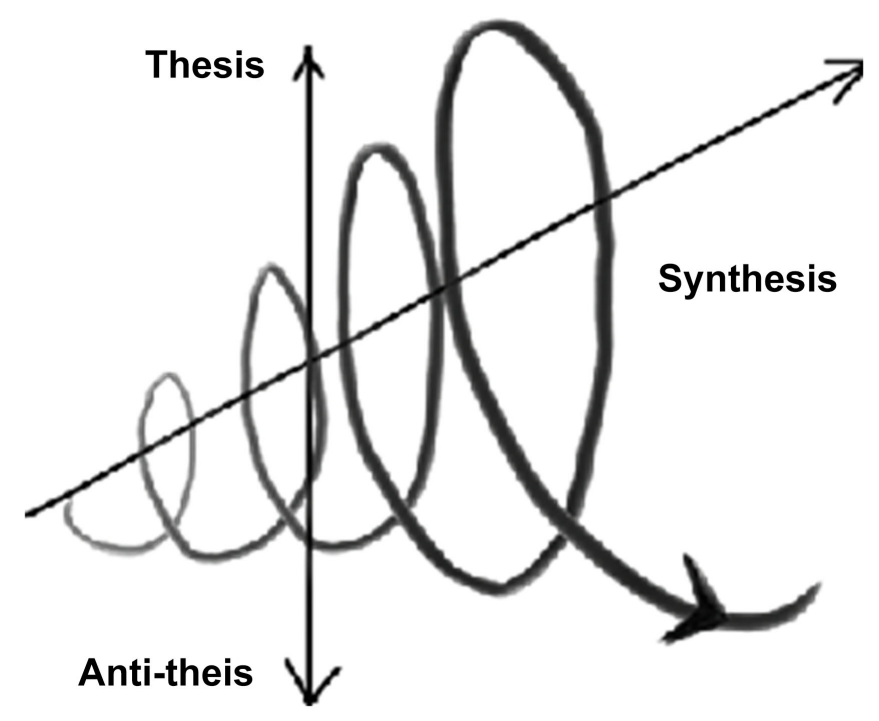

Figure 7. Model \#2 of the development of extinction and revival. 
Revival is not necessarily bringing back the past, while extinction is not always the destination. The case studies support that revival is more like a bridge between the past, present, and future, and destruction is the entrance to resurrection. Then, how should we open up new explorations through ending, and facilitate future development by transforming the past into a useful tool?

\section{Contribution}

Since the 1960s, designers and artists have been seeking new ways to challenge the dominant but rigid philosophy brought about by Modernism. World War II challenged the idea insisted by Modernism, which was "ultimately founded on a utopianism that upheld certain universal truths," (Gibbons, 2018) and "overturns people's belief in the progressive ideals" (No more rules, p.11). As universal truths were being challenged, a radical form of modernist design called for another movement-Postmodernism. Under the shadow of extreme ideologies, Postmodernism attempted to build a "complicitous relationship with the dominant culture" (No more rules, p.11) instead of making improvements. In the graphic design field, it was reflected in more self-reflexivity, trasient, ardent and disoriented forms, which were the opposite of the Modernist aesthetic and ideology.

From the 1980s to the current day, the most urgent social problems are considered to be serious political polarization (the extreme right and left), inequality (in gender, race, education), and general social insecurity that reveal the defect of the dominant capitalist system (Abramson, 2017). Under these circumstances, more movements such as Altermodernism, Metamodernism, Post-digital, and Performatism have arisen. While they compete with and often oppose one another, they also complement each other, which ultimately can be seen as the mediation between Modernism and Postmodernism as a way to better respond to social and political changes (Felluga, 2017).

However, neither Modernism nor Postmodernism has been overthrown. Although all the -isms propose new forms and ideologies that differentiate themselves from Modernism, they are limited in catering to specific contexts, and not the ideal and efficient framework for communication design. For instance, Dadaism as one of the representations of Postmodernism (dada de ha hi Dian) can communicate a powerful statement against bourgeois culture, but it is not the best way to communicate information regarding rationality and clarity. So how can we define and develop the most effective design approaches that best cater to the current stage of history?

It is hard to determine a movement while it remains fluid. While a movement is in progress, people cannot define its characteristics and its variations that are still uncertain or unknown. But, from another perspective, rather than naming the current movement, it is more important to think about how designers can utilize all the resources and information to which we have access. While design approaches can vary distinctively from one another through visual form and 
different messages, it is possible to develop a methodology that can be applied to various needs.

In the words of Mark Twain, "history does not repeat itself, but it does often rhyme" (Garson, 2014). People always find themselves in a position similar to one in the past. Therefore, it is logical to refer to the past for solutions. This thesis proposes the application of extinction and revival as a new methodology in design. Through evaluating the value that lies in the extinct, researching what caused the extinction, and building a connection between the contexts of both the past and the present, designers can develop a new strategy to respond to deep contemporary issues. In this way, design can offer people a fresh angle from which to understand history, better reflect on current conditions, and think ahead to social changes, to predict and have an impact on the future.

\section{Delimitation}

Extinction and revival as a design methodology was explored in this thesis through phenomenological approaches. Instead of discussing the reason behind the extinction or the revival, this research focuses on how to assign new messages to a project or create a new design work through destroying and renewing. The study will not include extinction in the field of zoology and ecology.

\section{Process and Methodology}

\subsection{The Study of Revival-Risograph Artifacts for Reviving the Extinct}

The first step of my research is conducting case studies based on the question-what is revival? During the research, I read references regarding extinction and revival and then reflected on them. It is a process which itself turns out to be one aspect of revival. In this project, I scanned the references, my notes, and other related references layer by layer using the Risograph. The subjects include a cookbook from the 17th century, a traditional Chinese family motto, extinct species and culture, Ice Piece by Andy Goldsworthy, and Rift by Michael Heizer. For the cook book, there is evidence of the forms of letters such as letter " $s$ ", are no longer used because of an antique technique-movable type. Also, certain spelling of words like the word "chyrurgery" for "cookery" is no longer used. Ice Piece and Rift are environmental art that are reclaimed by nature; the traditional Chinese family motto reflects discarded value from the past; and the extinct species and culture have permanently vanished from the earth. The fact that these references discuss extinct subjects is itself an act of revival made through documentation. While the scanned materials are the revivals of the subjects, the outcome (Figure 8) serves as a collection of visual representation of the process of revival.

\subsection{Torcher-The Message of Destruction}

Along with the contrast between the disappeared and the existing, destruction 

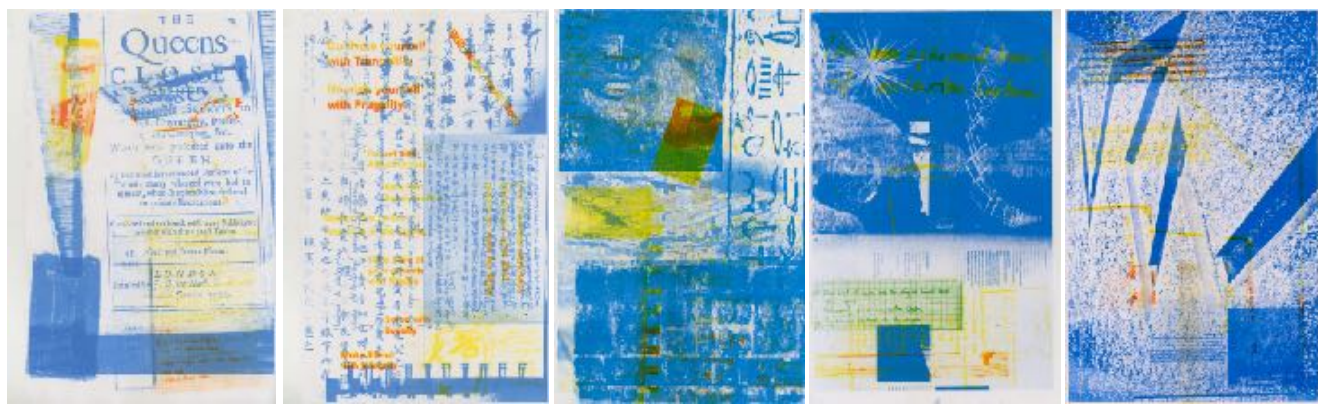

Figure 8. The Study of Revival.

itself can also send a strong message-the message of rejection or opposition. Torcher is a Rube Goldberg Machine consisting of Arduino and physical mechanisms. The project communicates the message of "Anti-retouched lifestyle" by destroying the subject to which I am opposed. As shown in the example, I project the retouched, small-focused pictures on paper. While the images are looping, the participant can decide which one they like and press the "like button" in front of them. The button triggers the Arduino to release an iron ball. The ball then rolls through a pathway which represents the process of editing, retouching and posting a picture. At the end of the pathway, I place a candle which is struck by the ball and tilts to burn the paper. After the paper is burned, a monitor displaying the larger view of the retouched image reveals (Figure 9). The dramatic performance where the opposed is burned to ash and the proposed is revealed intensifies the tone of the message.

\subsection{Resurrection-Extinction and Revival Depicted through Resurrecting a Celery}

I resurrected a dead celery root to explore and interpret the essence of revival. I put an abandoned root in water and documented the process of resurrection. While the new life grew from the middle, the peripheral started to rot. I refer to this phenomenon as the past that can never be revived, and what is resurrected is a new life form that shares the root with the extinct. Figure 10 shows this process. This theory is supported by research on the Renaissance, where the original Classical Antiquity was not the direct subject of 14th century Renaissance, but one that people exaggerated with imagination in order to effectively attack the social problems they were facing.

\subsection{A Book without Beginning and End}

One Hundred Years of Solitude, written by Gabriel García Márquez is a story that starts with an absence and ends with a disappearance. Through rounds of extinction and revival experienced by family members sharing the same names, everything built during these one hundred years is destroyed by hurricanes. This novel proposes another outcome of the concept of extinction and revival, that of ultimate extinction. How do we interpret this narrative? Does the ending erase the process, and we return to square one? Or are there traces that have been left 

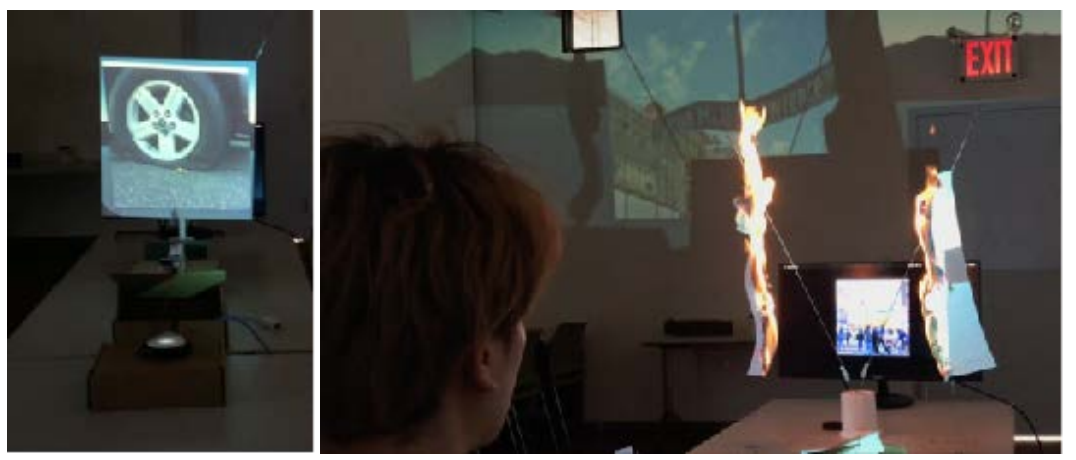

Figure 9. Torcher.
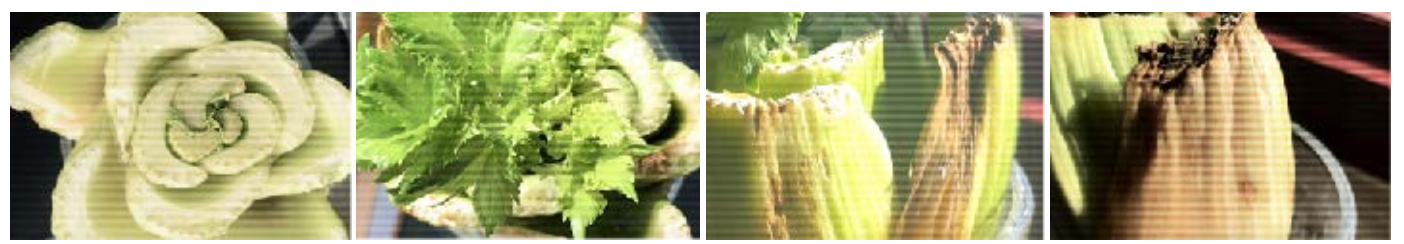

Figure 10. Resurrection.

behind even after the disappearance? In this project, I apply rhetoric on the subject of gardening and dream interpretation to present a different perspective on the story. Figure 11 is the documentation of the design result of One Hundred Years of Solitude.

\section{Capstone}

\subsection{The Extinction and Revival of Chinese Philosophy}

In this project, I explored the extinction and revival of Chinese philosophy; Confucianism, Mohism, Taoism, Legalism. As four major philosophical systems, they debated with each other throughout history. In different periods of history, the emperor adopted different philosophies based on what social and political conditions they faced. When one dynasty was overthrown by another, the prevailing ideology was also replaced. For example, the first emperor of Qin Dynasty burned Confucianism books and buried Confucian scholars alive because he needed to clear away the influence of Confucianism-the dominant philosophical system before Qin-to implement Legalism. Here, I designed a poster representing each philosophic system (Figure 12) and then fragmented them.

The destruction is a metaphor for heated debate and competition. Then, I used the fragments to create a sculpture (Figure 13) in the form of waves and flows to represent the revival after extinction. While being revived, the once extinct philosophical system would renew itself by absorbing ideas from other systems. The original washes away and the new ideas are developed based on "the dead" or the antithesis.

To further apply the methodology of extinction and revival, I destroyed the sculpture digitally and physically. Then, I revived the "extinct" project and used them to address a different topic. 

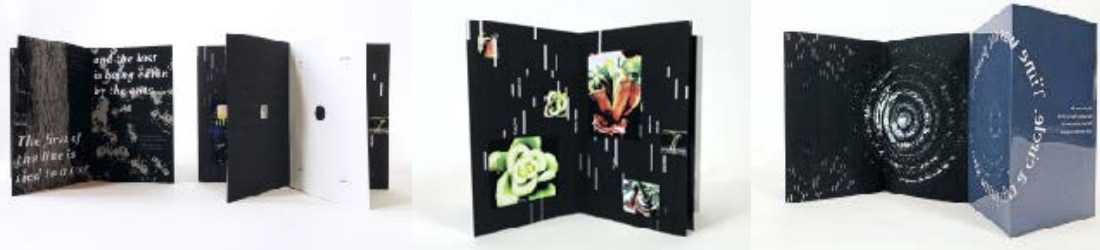

Figure 11. A Book without Beginning and End.

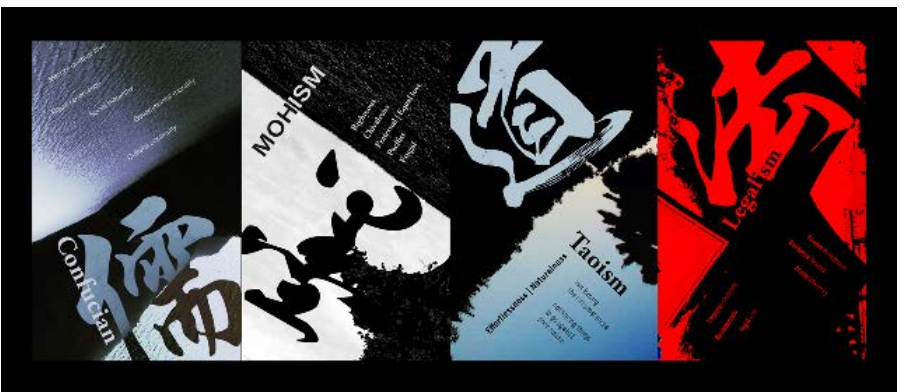

Figure 12. Posters of Four Philosophy Families.

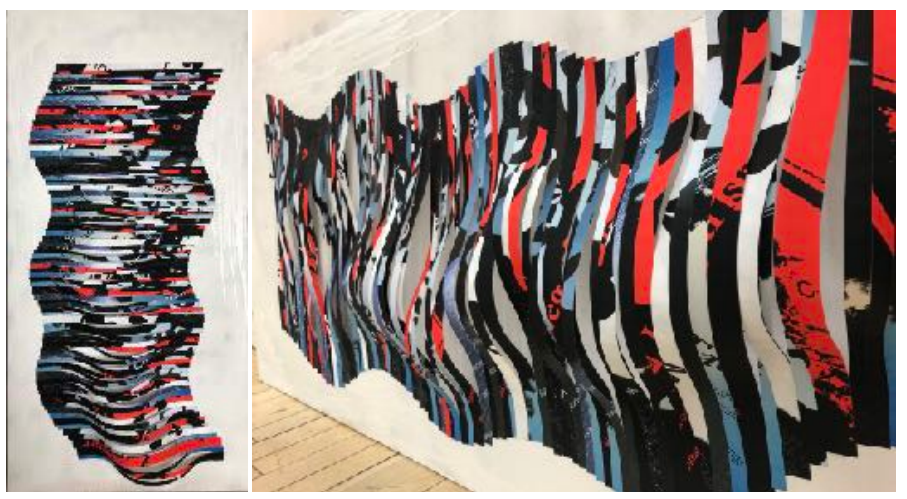

Figure 13. Sculpture-The Extinction and Revival of Chinese Philosophy.

\subsection{Digital Destruction-What We Believe in A.D. 2019}

When saving the image document of the sculpture as a postscript file, the image is written in lines of code. If I use text editor to manipulate a specific line of code, the corresponding line of pixels in the digital file will be garbled. At the beginning of the code, there is a section that defines the color used in the image. When I replace it with random code, the color will be modified. By covering, re-sequencing, and replacing the original coding, I made more and more stripes appear and the image loses details bit by bit. In the end, the only thing left to present is the pale pattern of the damaged sculpture (Figure 14).

The contention of different philosophical schools in the period of Warring Kingdoms in China took place around the same time with the Ancient Greco-Roman period. The ideologies formed under two political systems (Centralisation and Democracy) are significantly different from each other. As history developed, the two cultures that bred the traditional philosophies encountered 


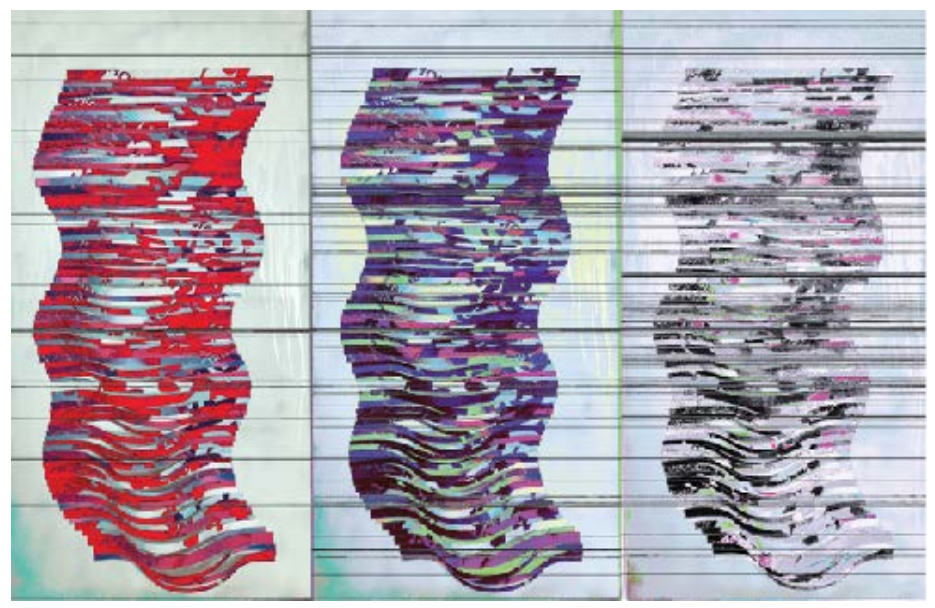

Figure 14. Documentation of Digitally Destroy the Sculpture.

and clashed with each other. However, while people argued over the differences, they also absorbed what they thought was wise and inspiring. Within each culture, when the traditional philosophy is challenged by the practice of modern social rules, some ideas are discarded as they no longer spoke to the present. To find a way that better communicates urgent issues, people sometimes look into the opposite idea of the discarded-a belief system from the other culture. And the way they refer to that idea becomes the revival.

After creating the pattern of degradation, I applied it to the topic regarding people's beliefs in modern society. I merged quotes from the period of Warring Kingdoms in ancient China, and quotes from the Ancient Greco-Roman period. When looking closely, it is hard to get any information from the overlaying quotes in different languages. However, when seen from a distance, the phrases "What We Believe in A.D. 2019" shown in Figure 15 and "What We Lost in A.D. 2019" shown in Figure 16 become legible. The quotes and beliefs are still there, but their meaning and influences are different for the people thousands of years later. Similarly, when replaced with code from other postscript documents, the original file loses information. People can still recognize the file from the silhouette, but when they take a closer look, the lines of pixels are all changed or destroyed-just like all traditional philosophies. What we believe in A.D. 2019 grows from the traditional, is developed through debate, and reformed in the process of extinction and revival.

On the other hand, traditional eastern and western philosophy can be seen as a thesis and anti-thesis pair. Throughout history, they absorb each other's ideology to complete themselves. In the end, while the traditional philosophy no longer prevails in modern society, it is the cornerstone for what people believe now.

Through this process of extinction and revival, the line between eastern and western philosophy becomes blurred. The traditional philosophy revived by us now no longer addresses the same issues, but they are transformed to address deeper contemporary issues. 


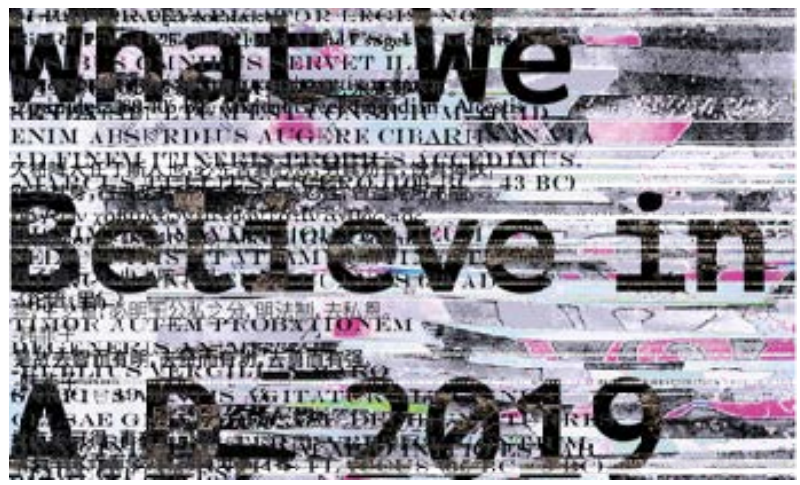

Figure 15. What We Believe in A.D. 2019.

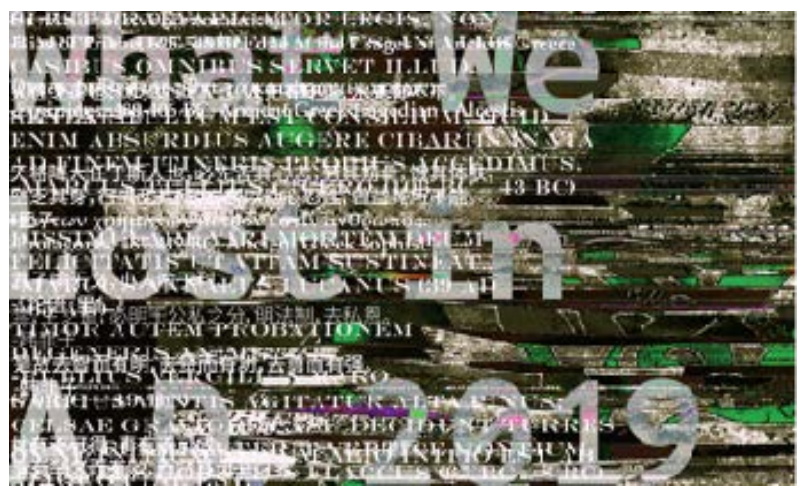

Figure 16. What We Lost in A.D. 2019.

\subsection{Physical Destruction-Philosophy in A.D. 2019}

In some Land Art projects, artists use the extinction of their artworks to convey a message. After the artifacts are destroyed, people rely on the documentation of the artifacts and the performance of destruction to revive the project. Here, I chose to burn the sculpture and make a video using the documentation to reflect on the theme "Philosophy in A.D. 2019". Figure 17 is a series of screenshots of the video.

While the sculpture depicts the diversity, wisdom, and aspiration of the philosophies in the period of Warring Kingdoms, the fire consuming the artifact communicates destruction of these ideas. In the video, I used close-up shots that reveal how the vivid colors gradually turn into ash gray, and the heat wave distorting the background. The lines that appear in the video were applied with a heat-wave effect to convey a feeling of turbulence. After the fire went out, I collected the ashes and place them in a box. The burnt sculpture and the box of residue became a metaphor for the extinct ideology and a reference toward further revival. In addition to this video, I mixed an audio track that combined the sound of burning and sweeping. The visual and the sound depicted a sense of disappearance and invalidation.

In A.D. 2019, traditional philosophies no longer exert their influence, and the power that created so much inspiration and progress in social development has been absent (extinct) for a long time. 

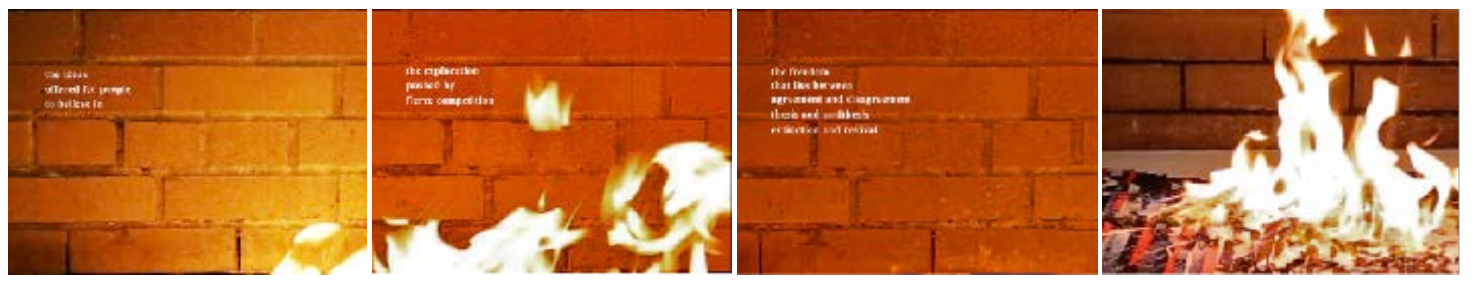

Figure 17. Screenshot of Philosophy in A.D. 2019.

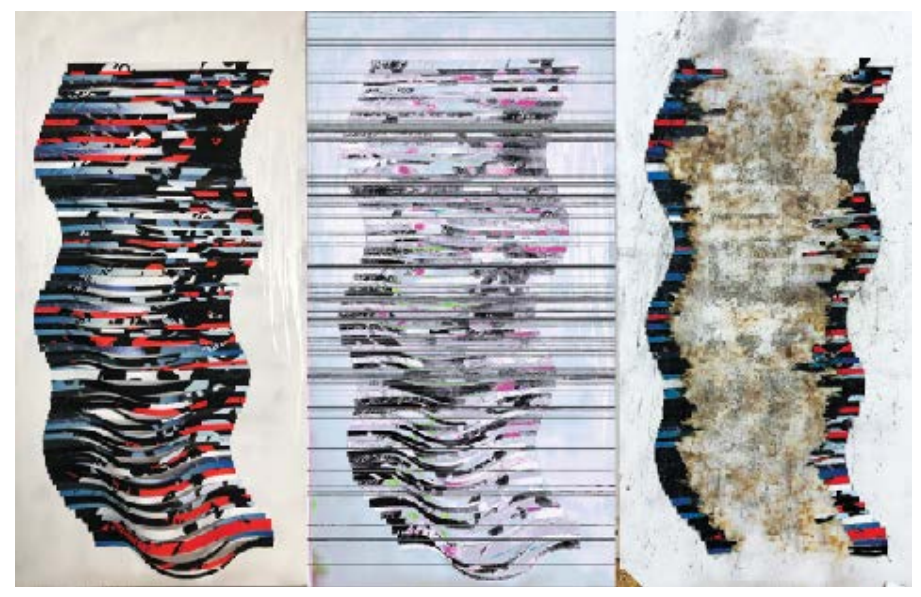

Figure 18. The digital and physical destruction of the original sculpture.

\section{Conclusion}

As shown in the process, with ongoing destruction, the artifact not only changed its appearance but also modified in meanings. The Extinction and Revival of Chinese Philosophy use fragmenting as a metaphor for the debate and competition between different philosophical systems and a way to decompose and recompose the original piece, thus transforming the posters into a 3D artifact. Then, What We Believe in A.D. 2019 applies a similar methodology to the digital archive of the sculpture. It features typography to communicate how the traditional eastern and western philosophies lose their original information over time and evolve by bringing in each other's idea during the process of extinction and revival. Altogether, the extinct and the revived traditional philosophy form contemporary beliefs. Last but not least, the video Philosophy in A.D. 2019, the destruction represents the extinction of the contention that created great thoughts and pushed society to move forward. It is what is absent and damaged in the content that arouses the audience's reflection-where is the contention? What is our modern philosophy without contention?

Figure 18 shows the transformation of the sculpture in the process of destruction and revival. This series of projects applies the methodology of extinction and revival to convey different messages towards related issues from different times and spaces (eastern and western). The information is built upon the annihilated projects or relies on the interpretation of the destruction of the project. The process and outcome echo the conclusion in the research, that instead of being the termination, extinction is the beginning of a new revival, and revival 
prompts a richer, deeper conversation using information extracted from the past.

The process of applying annihilation and resurrection as design methodologies reveals that a project, as a reflection of a certain problem or phenomenon, can carry more information than what the designer initially attempted to communicate. To some extent, there are alternative interpretations of a project in addition to the key message. Although the original design usually focuses on one perspective, one media, or one form, the audience is free to develop their own thoughts on the work or on the topic. The effect of applying this methodology also relies on the richness of the original work-the design that refers to a topic which reflects both the characteristics of an era and its impact on the future.

Through destroying the content, form or the physical artifact, the original message becomes faded or gets overthrown. This process opens up new possibilities for people to revive work by conveying messages of a related subject from a different perspective, and use and apply different forms, and communicate to a different group of audience. The outcome of extinction and revival can be seen as an expansion on the original project, as well as a new conversation between the past and the present.

Other than annihilation as a way to give the extinct new meanings, destruction itself can also be the message itself. In a contextual framework, there is a case where Banksy put his auctioned work through a shredder as a message against the current art system. Besides being a criticism and a metaphor of disagreement, destruction can be an expression of the endangered or absent condition of the content/subject. For instance, in Philosophy in A.D. 2019, the artifact, as a symbol for the Contention during the Warring Period, gets burnt, representing the fact that traditional philosophy no longer has great influence, and the competition that "created so much inspiration and progress in social development" and disappeared into past history.

Through this research I explored, revival as what allows designers to either interpret the extinct work in an alternative way, adapt it to another related context, or to use destruction (to make extinct) as a way to modify the original and convey new messages. This study proves that the methodology of extinction and revival can bridge the past, the present, and the future. Through reviving past works, a connection can be made between the past and current issues. Then, by comparing, analyzing, and reflecting on the extinct (past work) and the revived design, people will have a better understanding of how a certain subject develops through time, therefore having an insight into how it will evolve in the future.

The process of the capstone series suggests that designers can manipulate the message in a project through extinction and revival, and thus transforming the project into a reference or material that not only lives in a specific context (speaking to certain problems/phenomena) but can also be adapted into another related subject in the future. By adding new content, perspectives, and expanding the audience group, the life of the project can be eternal. When looking into how a project is being annihilated and resurrected over time, people can learn 
more information about the subject, analyze the issue from more perspectives in terms of time and space (eastern and western).

This process is also related to the Hegelian dialectic in which people tend to form a synthesizing perspective through the debate between thesis and anti-thesis. When being informed of the trail of development through extinction and revival (thesis and antithesis), a more informed balanced understanding can be reached towards the problem/phenomenon.

To sum up, this methodology of extinction and revival allows for an epistemological tracing through observing the pattern of historical development. The design methodology that was applied appears to support Mark Twain's pronouncement, "History always rhymes, but it never repeats itself." Through research, I found how history progresses through the switch between thesis and antithesis. Through physically and digitally destroying and renewing artifacts, I reflected on how new messages and interpretations can be created based on different subjects.

\section{Next Steps}

In the future, how the methodology of extinction and revival can be applied to other subjects can be further explored. Also, it is necessary to try to include more participants (designers) in the process. As multiple participants have different design styles, cultural background, and perspectives of thinking, there may be more opportunities for rich and through-provoking conversation.

\section{Acknowledgements}

My deepest gratitude goes first and foremost to Professor Alex Liebergesell for constantly giving me guidance and inspiration. Without Professor Liebergesell's insightful criticism and great dedication, this thesis could not have reached its present form.

\section{Conflicts of Interest}

The author declares no conflicts of interest regarding the publication of this paper.

\section{References}

Abramson, S. (2017, January 9). What Is Metamodernism? The Huffington Post. https://www.huffingtonpost.com/entry/what-is-metamodernism us $586 \mathrm{e} 7075 \mathrm{e} 4 \mathrm{~b} 0 \mathrm{a} 5 \mathrm{e}$ $\underline{600 \mathrm{a} 788 \mathrm{~cd}}$

Aminoff, B. Z. (2013). Entropic Definition of Human Happiness and Suffering. Philosophy Study, 3, 609-618.

Aminoff, B. Z. (2014). On Mechanisms of Human Behaviour: Legends of Desirable Anti-Entropy Deficiency Phenomenon Theory. Indian Journal of Health \& Wellbeing, 5, 427-436.

http://search.ebscohost.com/login.aspx?direct=true\&db=aph\&AN=97584943\&site $=$ eds -live 
Bubb, H. (2006). A Consideration of the Nature of Work and the Consequences for the Human-Oriented Design of Production and Products. Applied Ergonomics, 37, 401-407. https://doi.org/10.1016/j.apergo.2006.04.004

Dance Magazine (2013). After the Revolution: As the Rite of Spring Turns 100, We Take a Look at the Reverberating Impact. Dance Magazine, No. 2, 32.

http://search.ebscohost.com/login.aspx?direct=true\&db=edsgao\&AN=edsgcl.31758773 $\underline{8 \text { \&site }=\text { eds-live }}$

ELA (Endangered Language Alliance) (2012). Why Linguistic Diversity-Introduction. https://www.elalliance.org/about/why-linguistic-diversity/introduction

Felluga, D. (2017, January 31). General Introduction to the Postmodern. General Introduction to Postmodernism. Purdue College of Liberal Arts. https://www.cla.purdue.edu/english/theory/postmodernism/modules/introduction.html

Garson (2014, January 12). History Does Not Repeat Itself, But It Rhymes. Quote Investigator. https://quoteinvestigator.com/2014/01/12/history-rhymes

Gibbons, A. (2018, September 3). Postmodernism Is Dead. What Comes Next? TheTLS, The Times Literary Supplement.

https://www.the-tls.co.uk/articles/public/postmodernism-dead-comes-next

Guffey, E. E. (2006). Retro: The Culture of Revival. Reaktion. http://search.ebscohost.com/login.aspx?direct=true\&db=cat06956a\&AN=prt.b1217841 \&site $=$ eds-live

Hartnett, J.-P. (2016). Killing Joke at the Expense of History. Eye Magazine. https://www.eyemagazine.com/feature/article/killing-joke-at-the-expense-of-history

Jones, J. (2018, October 8). Why Putting $£ 1 \mathrm{~m}$ through the Shredder Is Banksy’s Greatest Work. The Guardian.

https://www.theguardian.com/artanddesign/2018/oct/08/why-shredder-is-banksy-grea test-work

Limnatis, N. (2010). The Dimensions of Hegel's Dialectic. Continuum. http://search.ebscohost.com/login.aspx?direct=true\&db=nlebk\&AN=314899\&site=edslive

McKernan, B. (2016, November 15). Isis Destroys 3,000 Years of History in Two Months of Destruction. The Independent.

https://www.independent.co.uk/news/world/middle-east/isis-mosul-iraq-army-terroris ts-destroy-demolish-nimrud-temples-artefacts-a7418136.html

Moorton, R. F., \& Titchener, F. B. (1999). The Eye Expanded: Life and the Arts in Greco-Roman Antiquity. University of California Press.

http://search.ebscohost.com/login.aspx? direct=true\&db=nlebk\&AN=13123\&site=eds-li ve

Orlov, P. (2018, March 19). What You Could Take Away from "David Bowie Is". The Current.

https://www.thecurrent.org/feature/2018/03/19/david-bowie-is-exhibit-brooklyn-muse um

Sparke, P. (2010). Retro: The Culture of Revival. Design Issues, 26, 80-81.

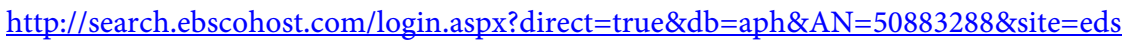
-live https://doi.org/10.1162/DESI r 00006

The MET (2018a). Madonna and Child.

https://www.metmuseum.org/art/collection/search/435658

The MET (2018b). Virgin and Child. 
https://www.metmuseum.org/art/collection/search/435765

Tresoldi, E. (2016). Basilica di Siponto.

https://www.edoardotresoldi.com/works/basilica-di-siponto

Webster, G. (2018, January/February). The Rise of Riso. Communication Arts, 24-27. 